\title{
Argonne National Laboratory high-performance network support of APS experiments
}

\author{
M. J. Knott \\ Accelerator Systems Division, Argonne National Laboratory. 9700 South Cass Avenue, Argonne, \\ Illinois 60439 \\ R. J. McMahon \\ Electronics and Computing Technologies Division, Argonne National Laboratory 9700 South Cass \\ Avenue, Argonne, Illinois 60439
}

(Presented October 19, 1995)

Argonne National Laboratory is currently positioned to provide access to high-performance regional and national networks. Much of the impetus for this effort is the anticipated needs of the upcoming experimental program at the APS. Some APS Collaborative Access Teams (CATs) are already pressing for network speed improvements and security enhancements. Requirements range from the need for high data rate, secure transmission of experimental data to the desire to establish a "virtual experimental environment" at their home institution. In the near future, $155 \mathrm{Megabi} / \mathrm{sec}(\mathrm{Mb} / \mathrm{s})$ national and regional asynchronous transfer mode (ATM) networks will be operational and available to APS users. Full-video teleconferencing, virtual presence operation of experiments, and highspeed, secure transmission of data are being tested, and in some cases, will be operational. We expect these efforts to enable a substantial improvement in the speed of processing experimental results as well as an increase in convenience to the APS experimentalist. (01995 American Institute of Physics.

\section{INTRODUCTION-THE DATA EXPLOSION}

The Advanced Photon Source (APS) will enable scientists to study more complex systems, faster reactions and processes, and to gather data at a greater rate and level. of detail than has been possible to date. Each of these factors has the independent potential of increasing by a large degree the amount of experimental data collected. This data could be stored at the experiment site or in an APS or Argonne data storage facility, or it could be stored on optical disks and transported to the scientist's home institution for storage and use. However, the continuing growth and increasing speed of regional and national networks will make possible the quick relocation of the data and will open possibilities for rapid interaction of the expose/analyze/modify/expose cycle for certain types of experiments.

In addition, as more and faster data networks become available, other uses of these networks, not normally thought of, will become realizable and even attractive for the APS experimentalists. Network-based teleconferencing, remote monitoring and control of some portion of the experiment itself, and even educational experiences based on display of the data from a running experiment will all be within the realm of possibility.

\section{APS NETWORK INFRASTRUCTURE}

To provide for adequate security, initial bandwidth and bandwidth growth, and user-to-user separation, the APS is installing a network infrastructure based initially on FDDI $(100 \mathrm{Mb} / \mathrm{s})$ service to each lab office module (LOM). Each user group, known as a Collaborative Access Team (CAT) can receive Ethernet (10 Mb/s) of, FDDI service from the router and hubs located in each LOM. An average of three network subnets per sector can be provided with the APS Class-B license to allow for address separation between CATs and their beamlines.

Figure 1 shows the APS FDDI network as a ring network. It is physically a "collapsed ring" and will allow an upgrade to switched FDDI in the future to gain higher aggregate data throughput. Dark fibers are available for special CAT needs. Also shown in Figure 1 is an asynchronous transfer mode (ATM) switch connected to all LOMs. This switch will be utilized by those CATs which require very high data transfer rates -- initially up to $622 \mathrm{Mb} / \mathrm{s}$. The ATM protocol allows data, voice, and video to be intermixed while providing priority and "class-ofservice" to be maintained.

DISTRIBUTION OF THIS DOCUMENT IS UNLMMTED

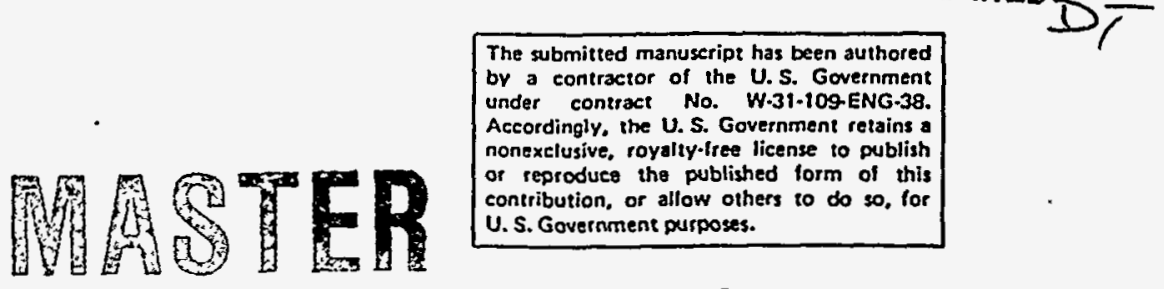




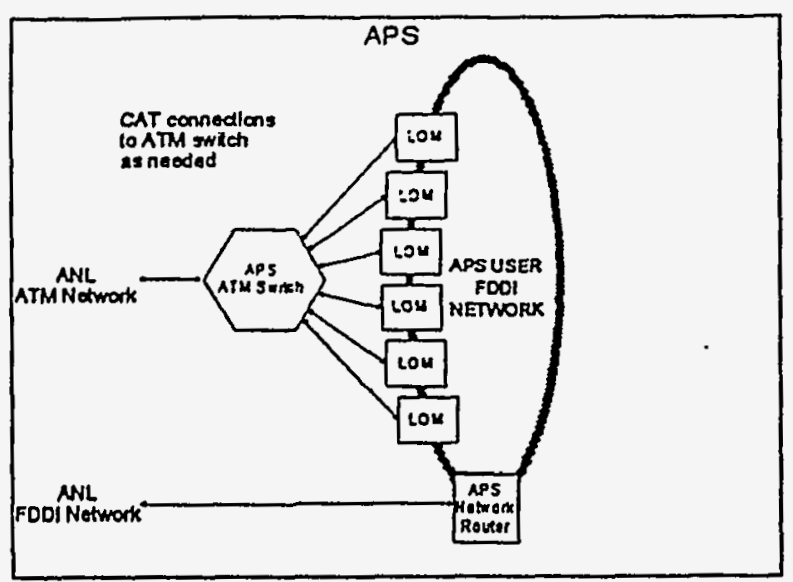

Figure 1

\section{LABORATORY-WIDE NETWORKS}

The Argonne network topology consists of a hierarchy of networks, including local area networks based on Ethernet or FDDI encompassing buildings or programs, a Lab-wide network currently based on FDDI, and gateways to national and regional networks. Argonne is currently starting to deploy ATM technology and the APS ATM switch will be directly connected to the Argonne campus ATM switch, shown in Figure 2, which in turn will provide connections to Argonne's central computing and file services.

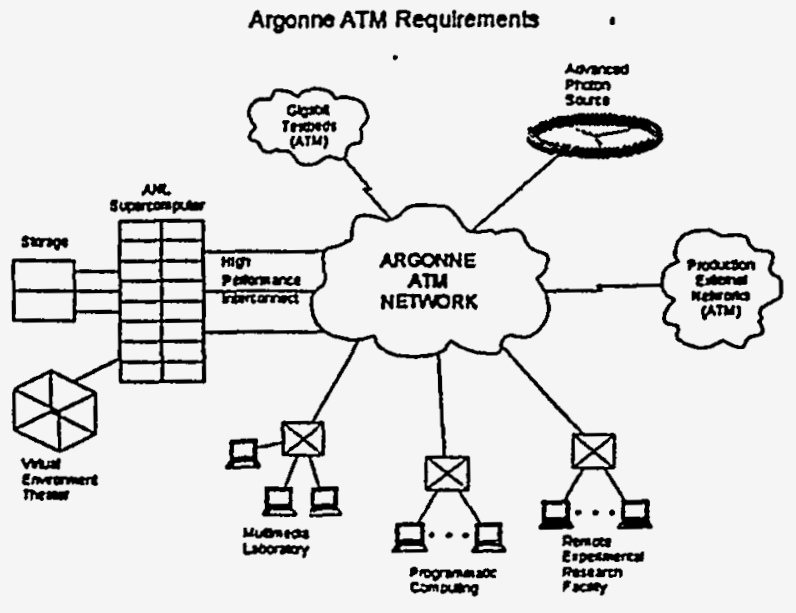

Figure 2

Perhaps more important to CATs based outside of Argonne is that the Argonne ATM switch will provide direct, high-bandwidth connections to several regional and national networks, most of which will also provide high-bandwidth ATM service in the near- or long-term.

\section{NATIONAL AND REGIONAL NETWORKS}

Argonne National Laboratory is positioned to provide high-performance national and regional network connectivity for support of APS experiments. The Laboratory provides computer users with state-of-the-art connectivity to ESnet, CICnet, and MREN and is working with the major carriers (e.g., Ameritech, AT\&T, MCI, and Sprint) to further develop the Laboratory networks as commercial network services are deployed. The following sections describe these programs.

\section{ESnet}

The U.S. Department of Energy's (DOE) Mathematical, Informational and Computational Sciences Division (MICS) operates a national network called the Energy Sciences network (ESnet). ESnet provides connections to a number of DOE backbone sites, including Argonne. ESnet is an ATM network that is run by the National Energy Research Supercomputer Center (NERSC) at Lawrence Livermore National Laboratory in California. Argonne is working with NERSC to upgrade its ESnet connection from $45-\mathrm{Mb} / \mathrm{s}$ to $155-$ $\mathrm{Mb} / \mathrm{s}$ in FY1996. Sprint is the national ATM carrier for ESnet. The ESnet national backbone network is shown in Figure 3.

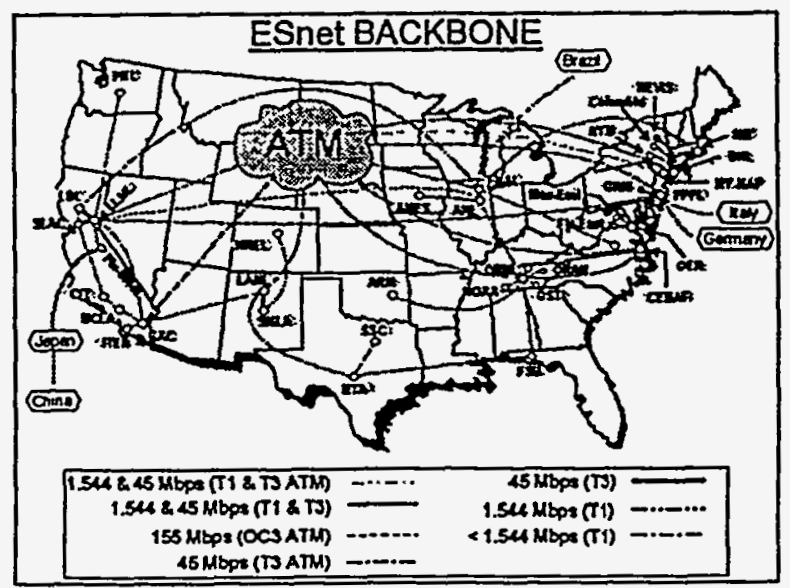

Figure 3

\section{CiCnet}

The Consortium for Institutional Cooperation (CICnet), which provides data communication links to many Midwestern regional universities and other regional sites, is shown in Figure 4.

$\mathrm{MCI}$ is the carrier for CICnet and provides network services to CICnet via a $45-\mathrm{Mb} / \mathrm{s}$ connection to the $\mathrm{MCI}$ national network. Argonne is 
a member of CICnet and connects to ClCnet over four 1.544-Mb/s links.

We are working to keep bandwidth of CICnet just ahead of need.

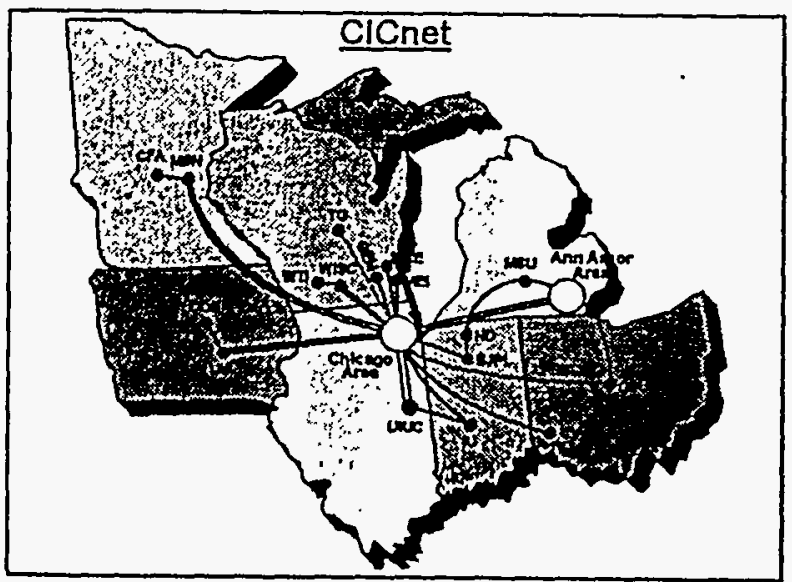

Figure 4

\section{MREN}

The Metropolitan Research and Education Network (MREN) is an interorganizational highperformance network that interconnects the University of Chicago, Argonne National Laboratory, Fermi National Accelerator Laboratory, Northwestern University, and the University of Illinois at Chicago via the Ameritech Public Data Network (APDN). The APDN runs over an optical carrier 48 (OC48 - 2.488 Gigabit/sec) backbone. Argonne National Laboratory connects to the APDN backbone at OC3 $-155 \mathrm{Mb} / \mathrm{s}$ as shown in Figure 5.

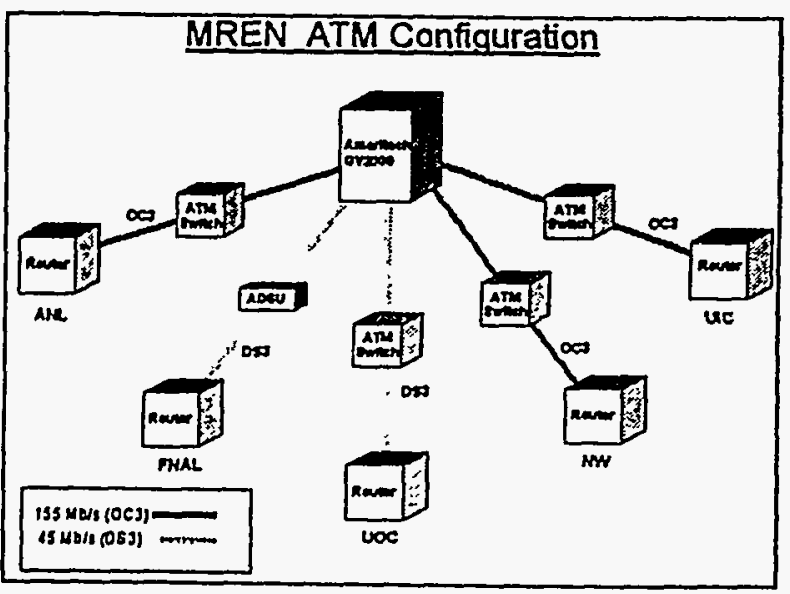

Figure 5

\section{Commercial Network Services}

Argonne is working with Ameritech, AT\&T, $\mathrm{MCI}$, Sprint, and other communications providers to allow Argonne to connect to the commercial network services as it is deployed. There is a business case that is being formulated to allow APS CATs to reach their APS experimental facilities over a high-performance network from their home sites. The MCI example shown in Figure 6 is an example of the connectivity options being discussed with the carriers.

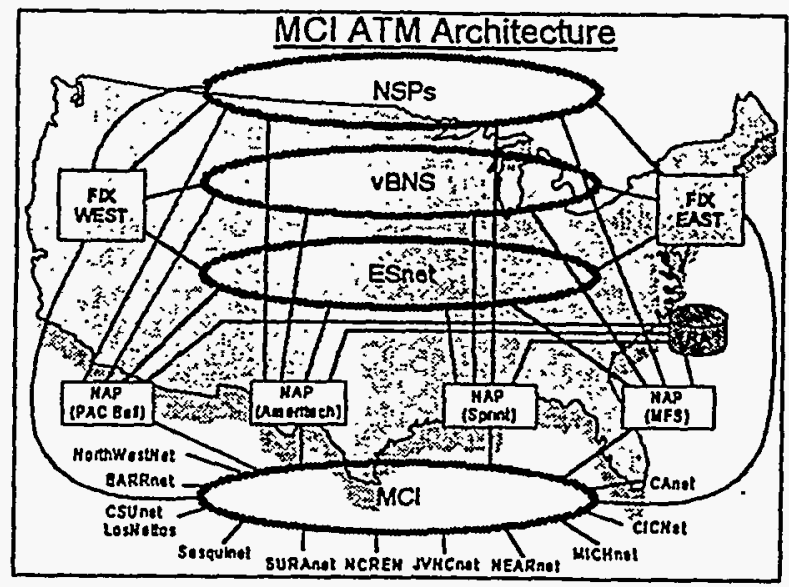

Figure 6

\section{NETWORK SECURITY}

Argonne runs a laboratory networking environment that includes Kerberos V4 and the Andrew File System. In addition, Argonne chairs an ESnet authentication project that deals with authenticating users working at autonomous sites who need to share data. By using Kerberos V5. security services, a working environment can be established across a wide-area network without using passwords across the network. Security options are dependent upon the CAT team's home site security. The following security options are available to the APS user community:

- Sites can be responsible for their own security by using encryption hardware as needed

- Andrew File System using access control lists and Kerberos V4

- Kerberos V5

- Open Software Foundation (OSF) Distributed Computing Environment (DCE) with Kerberos V5 plus extensions 
- Standard operating system security features (more security features are being added to standard operating system products)

\section{RECOMMENDATIONS}

As the APS network infrastructure, the ANL Laboratory Network, and external networks continue to evolve, the CATs can get updated information on these networks through the APS WWW at URL http://www.aps.anl.gov/welcome.html

\section{RECOMMENDED PUBLICATIONS}

The final report and recommendations of the ESnet Authentication Pilot Project is on the WWW at URL http://www.es.net/pub/esnet-doc/auth-andsecurity

\section{ACKNOWLEDGMENTS}

This work was supported by the U.S. Department of Energy, Office of Basic Energy Sciences, under Contract No. W-31-109-ENG-38.

\section{DISCLAIMER}

This report was prepared as an account of work sponsored by an agency of the United States Government. Neither the United States Government nor any agency thereof, nor any of their employees, makes any warranty, express or implied, or assumes any legal liability or responsibility for the accuracy, completeness, or usefulness of any information, apparatus, product, or process disclosed, or represents that its use would not infringe privately owned rights. Reference herein to any specific commercial product, process, or service by trade name, trademark, manufacturer, or otherwise does not necessarily constitute or imply its endorsement, recommendation, or favoring by the United States Government or any agency thereof. The views and opinions of authors expressed herein do not necessarily state or reflect those of the United States Government or any agency thereof. 